\title{
PROCESSOS DE REFERENCIAÇÃO NO HIPERTEXTO
}

\author{
ANTONIO CARLOS S. XAVIER \\ Universidade Federal de Pernambuco ${ }^{1}$
}

\begin{abstract}
This article aims to examine the functioning of the hyperlinks in the hypertexts and to discuss how they help to do the semantic, cognitive and interactional references. Hyperlinks are the fundamental instruments of the eletronic texts; they allow to come to one's mind the bigger interconnection of texts, informations and knowledges of the world. They are vetorial-deitic elements that move the reader to the other virtual pages and hypertexts so fastly and economically. They achieve a complex process of auto and hetero-referenciation: co-hypertext and pan-hypertext. Then, the hyperlinks present to browsers and readers one different way to make referenciation. How this happens in the hypertext? This paper will try to show it.
\end{abstract}

\section{INTRODUÇÃO}

Parar o mouse em um certo espaço da tela do computador e clicar sobre um determinado hiperlink tem sido uma das ações mais comuns atualmente na vida dos cerca de 300 milhões de usuários da rede mundial de computadores espalhados pelo planeta. Mergulhar eletronicamente por determinadas palavras marcadas no texto digital tem se constituído a prática fundamental dos hiperleitores, quando da sua leituranavegação nas miríades de páginas indexadas à web. Entretanto, a grande maioria daqueles que têm se utilizado dos hiperlinks, ao "folhearem" as páginas eletrônicas, ainda não se deu conta da enorme complexidade que envolve esta atitude aparentemente simples; muitos não se aperceberam dos engenhosos processos de referenciação desencadeados pelos hiperlinks nem atentaram para a inevitável multiplicidade de trilhas cognitivas que eles apontam durante a leitura-navegação.

O objetivo fundamental deste artigo é discutir, ainda que com certa limitação, o funcionamento dos hiperlinks dentro de uma perspectiva lingǘstico-enunciativa e sócio-cognitiva, bem como teorizar sobre o seu papel enquanto elemento de referenciação digital em Hipertextos. Dizendo de uma outra maneira, queremos desenvolver uma reflexão em torno de duas questões, que acreditamos fundamentais,

\footnotetext{
${ }^{1} \mathrm{O}$ autor é professor do Depto de Letras da UFPE e doutorando em Lingüística na Unicamp.
} 
cujas consequiências incidem diretamente sobre as formas de ler e compreender os discursos inscritos na tela digital:

1) Quais são as características técnicas e enunciativas dos hiperlinks?

2) Qual o seu papel no processo de referenciação digital, quando da leitura de Hipertextos?

\section{PRESSUPOSTOS FUNDAMENTAIS: LÍNGUA, TEXTO, HIPERTEXTO E REFERENCIAÇÃO}

Para tanto, é preciso, antes, explicitarmos qual a concepção de língua, de texto, de Hipertexto e de referenciação que subjaz aos posicionamentos aqui adotados e que sustentam a idéia central a ser defendida ao longo deste artigo.

\section{2.a. Noção de Língua}

A LÍNGUA é um jogo pleno de atividades verbais, heterogêneas, interacionais, cognitivas, sociais e históricas interdependentes e interrelacionadas (Beaugrande 1997). Ela é resultado de ações lingüísticas, sociais e cognitivas dos sujeitos que as realizam no interior de eventos reais, i.e., envoltos em acontecimentos discursivos situados na história. Ela é compreendida como um processo repleto de ações verbais integradas produzidas por agentes sociais historicamente constituídos. Estes agentes dotados de volição própria inferem, pressupõem e geram sentidos on-line a partir das pistas lingüísticas de acordo com o contexto de sua produção. Nestas ações verbais estão envolvidas operações cognitivas, cujas decisões interpretativas (avaliações, retomadas e conclusões) dos sujeitos são negociadas momento a momento e modeladas conforme o desenrolar da interação social que lhe deu origem.

\section{2.b. Concepção de Texto}

Textos são aqui concebidos como "FORMAS DE COGNIÇÃO SOCIAL. São muito mais que "roupagens do pensamento" (como advogam alguns cognitivistas). $O$ texto é, antes de tudo, constitutivo do próprio saber, é o próprio conhecimento em si, haja vista que todo conhecimento declarativo circulante em uma dada sociedade é um conhecimento lingüístico e social alicerçado em certos modos e gêneros textuais. (Antos 1997). Os textos, eles mesmos, são a essência do conhecimento, matéria-prima do saber e não só recursos técnicos que viabilizam a exposição de saberes outros in abstracto que ganham visibilidade e concretude, quando textualizados. Além de permitir tecnicamente a simultaneidade entre a escrita e a ciência, os textos são elementos-base desta mesma ciência, que deles se utiliza tanto como suporte para sistematização, organização e conservação do novo saber descoberto, quanto como componente gerador de outros saberes científicos. Ou seja, eles são tão essenciais para a produção do conhecimento, quanto para a sua projeção e divulgação no mundo. 
Assim como as teorias, ontologicamente, os textos, além de serem formas complexas e perspectivadoras do conhecimento, parecem criar mundos de conhecimentos que são textualizados lingüisticamente. Eles disponibilizam aos homens uma espécie de ordem cognitiva do mundo e seu funcionamento. Ao mesmo tempo em que organizam e selecionam a cognição humana, eles evitam a sua entropia, impedem, de uma certa forma, que o conhecimento se perca.

\section{2.c. Definição de Hipertexto}

Mas o que é mesmo o HIPERTEXTO ? A partir desta concepção de texto como 'forma de cognição social que organiza e constitui o conhecimento' e com o desenvolvimento das novas tecnologias digitais, permitindo a diminuição do tempo e das distâncias da interação verbal entre os atores sociais, podemos observar que, uma vez digitalizados, os textos parecem abrir caminho para a chegada do Hipertexto, um constructo semiótico produzido sobre a tela do computador, um novo modo de enunciação que surge no seio da contemporânea sociedade da informação neste século XXI.

Theodore Nelson, o primeiro a utilizar o termo "hipertexto", assim o descreve em Literary Machine (1993):

1. Trata-se de um conceito unificado de idéias e de dados interconectados de modo que eles podem ser editados sobre a escrita do computador;

2. Um instância com a qual se pode religar as idéias e os dados, que evidencia a dupla vocação do Hipertexto: um sistema de organização de dados e um modo de pensar.

O Hipertexto pode ser considerado, ao mesmo tempo, um sistema material e uma tecnologia intelectual, em que o ator humano interage com as informações que ele faz nascer de um percurso (navegação) virtual e as modifica em função de suas representações individuais (sistemas de crenças, valores, ideologias) e suas demandas circunstanciais. Em outras palavras, o leitor do Hipertexto não tem compromisso com uma seqüenciação a priori rígida e inviolável durante a sua leitura-nevegação (Xavier 1999a).

Cabe aqui uma séria advertência: não se pode confundir a noção de deslinearidade com a de descontinuidade potencial do discurso, como bem nos lembra Clément (1995). A não-linearidade deve ser definida do ponto de vista do dispositivo material e não do ponto de vista do discurso. Não-linearidade não significa obrigatoriamente a não continuidade seqüencial da materialidade discursiva, pois na recepção dos discursos essa é uma decisão exclusiva do leitor, em qualquer tipo, modo ou tecnologia de enunciação.

Já a descontinuidade é uma forma de montagem pela qual o dizer acha a sua coesão. $\mathrm{O}$ discurso na superfície digital fortalece-se não devido à linearidade de um desenvolvimento temático qualquer, mas por causa da rede subterrânea de filamentos ditos, não-ditos e ecoados, ainda que à distância, entre os temas afins vinculados entre si por fortes ou tênues relações interdiscursivas/intertextuais. O Hipertexto, então, 
convida o leitor a re-organizar esta estrutura originalmente descontínua, a bel-prazer, e ele assim o faz em seu "surfe" virtual, em suas idas-e-vindas a certos hiperlinks, nós ou sítios durante a leitura-navegação.

A especificidade do Hipertexto repousa exatamente nesta falta de compromisso com uma ordem hierárquica, quase obrigatória, a ser seguida, instituída pela linearidade própria dos textos impressos, e agora questionada, bem como pela sua capacidade de re-inventar novas formas e modos discursivos.

Portanto, o Hipertexto parece só se deixar "decifrar" fragmentariamente, funcionando como uma "materialidade discursiva", ao mesmo tempo, mutante e plural, cuja inteligibilidade potencial é conquistada lentamente por meio dos mergulhos nos hiperlinks. Em suma, podemos dizer que, por não seguir a lógica seqüencial dos discursos em celulose, o texto eletrônico apresenta-se como um espaço semântico a construir ou em vias de construção pela intervenção criativa e exploratória de seus usuários.

\section{2.d. Perspectiva de Referenciação}

Os mergulhos em busca de significação por meio de engenhocas digitais (hiperlinks) manifesta uma outra e talvez mais importante característica do texto eletrônico: um modo digital de referenciar. Cumpre, então, explicitar o que se entende por referenciação e como ela se dá no texto eletrônico.

É sob a ótica da Lingüística Sócio-Cognitiva, mais precisamente a vertente desenvolvida pelo grupo de pesquisadores franco-suíços ${ }^{2}$, que os processos de referenciação e inferenciação dos hiperlinks e seu papel catafórico e dêitico-vetorial para a construção da coerência do Hipertexto serão aqui abordados.

Logo, Referir, nos termos de Apothèloz \& Reichler-Béguelin (1995) e Mondada $\&$ Dubois (1995), deixa de ser um ato de rotular ou afixar previamente um adesivo sobre um dado objeto do mundo e passa a ser uma atividade discursiva gerada conjuntamente na interação entre indivíduos, que produzem, pela linguagem, realidades cognitivo-discursivas dentro do fervilhante desenrolar das "intersubjetividades negociadas publicamente no mundo” (Mondada e \& Dubois, 1995:276).

\section{TIPOS E FUNÇÕES DOS HIPERLINKS}

Normalmente, nas páginas eletrônicas iniciais, estão ancorados dois tipos de hiperlinks: Links-Fixos, ou seja, aqueles que têm um espaço estável e constante no site;

\footnotetext{
${ }^{2}$ Trata-se da equipe de lingüistas da Universidade de Freibourg (Alain Berrendonner, Marie-José ReichlerBéguelin, Françoise Zay, Denis Apothéloz, Laurence Benetti, Catherine Chanet e Jöel Gapany), que entre os anos de 1991 e 1994 desenvolveu projeto de pesquisa sobre referenciação, tendo mantido estreito contato com o projeto "A Anáfora e seu Tratamento" realizado pelo Réseau Cognisciences Est, do qual participaram Michel Charolles e Georges Kleiber. Com a mesma orientação teórica trabalham Laurence Kister, Lorenza Mondada e Daniére Dubois. Todos esses pesquisadores tiveram os resultados dos seus trabalhos de pesquisa publicados no livro Du Sintagme Nominal aux Objets-de-Discours organizado por Berrendonner \& Réichler-Béguelin (1995).
} 
e Links-Móveis, isto é, aqueles que flutuam no site, variando a sua aparição de acordo com a conveniência do enunciador, i.e., o produtor/autor da página eletrônica. A maioria dos portais de acesso, inclusive o UOL, oferece geralmente seus principais serviços em hiperlinks do primeiro tipo, conservando-os todos nos mesmos lugares desde o lançamento oficial do portal, a fim de facilitar a localização e memorização espacial pelo usuário, criando-lhe expectativa do que se pode achar naquele espaço virtual.

Para os objetivos deste artigo, interessa definir os hiperlinks basicamente a partir de duas perspectivas diferentes, mas complementares: enquanto Dispostivo TécnicoInformático e como Mecanismo de Referenciação Digital.

\section{3.a. Dispositivo Técnico-Informático}

É ele que dá origem, viabilidade e visibilidade ao texto eletrônico e lhe permite existir interconectado. Ele torna possível o diálogo digital entre documentos-saberes.

Enquanto dispositivo técnico-informático, os hiperlinks, vinculam mútua $e$ infinitamente pessoas e instituições, entrelaçando-as em uma teia virtual de alcance mundial a qualquer hora do dia. Estes links permitem ao hiperleitor realizar livremente desvios, saltos e fugas instantâneas para outros locais virtuais da rede, de modo cômodo, prático e econômico. A distância de um indivíduo a outro, de um texto a outro, de uma idéia a outra passa a ser medida por céleres clicks-de-mouse sobre estas inteligentes engenhocas digitais.

Tais vetores informáticos por onde escorrem os textos eletrônicos são distribuídos e organizados estrategicamente pela superfície das home-pages que circulam no ciberespaço, encadeando-as entre si num complexo processo de auto e héteroreferenciação.

\section{3.b. Mecanismos de "Referenciação Digital"}

No que tange às páginas iniciais dos portais de acesso à Internet, os links, entre outras atribuições, servem para orientar e monitorar a leitura do visitante, sugerindo-lhe outros lugares disponíveis dentro do próprio website ou fora dele. Em tais portos-depassagem digitais, os hiperleitores encontram muitas opções de serviços, informação e, principalmente, lazer, enquanto navegam.

Não é qualquer palavra, ícone ou fotografia no texto eletrônico que pode ou merece receber um hiperlink. Em tese, somente os que de fato remetam o hiperleitor a outros conhecimentos relevantes ao todo daquela página virtual devem ser "linkados". Sendo assim, o processo de referenciação digital dentro do Hipertexto nasce e passa impreterivelmente pelos hiperlinks que vão ponteando discursos e saberes diversos na enorme malha digital.

Mas em que sentido estamos tratando a expressão "referenciação digital"? Certamente não a estamos empregando no sentido de remissão a referentes dentro do mesmo texto, como habitualmente tem sido utilizado na Lingüística Textual. Alguns autores (Koch \& Marcuschi 1998) têm procurado separar alguns termos que têm sido 
geralmente tomados um pelo outro e quase nunca distinguidos em suas propriedades discursivas, tais como retomada (que implica remissão e referenciação), remissão (que implica referenciação e não necessariamente retomada) e referenciação (operação lingüístico-cognitiva que não implica remissão pontualizada nem retomada específica).

Esta referenciação pós click-de-mouse abre para o usuário o franco e rápido acesso a Hipertextos outros. Ou seja, essas referenciações digitais produzem pulos instantâneos para fora da "materialidade" enunciativa hipertextual imediata sem o compromisso de retomar quaisquer referentes anteriores, isto é, sem a obrigação de recategorizar ou fazer progredir a cadeia referencial no nível co-textual (Koch 1997).

$\mathrm{O}$ modo digital de referenciar proposto pelos hiperlinks no hipertexto articula as informações linkadas basicamente de duas formas: co-hipertextual e panhipertextualmente.

\section{a) Referenciação Digital Co-Hipertextual}

Por nos faltar uma melhor terminologia no momento, chamaremos de "cohipertextuais" as referências digitais feitas por hiperlinks dentro de um mesmo website. Vejamos, por exemplo, a organização visual (design) da página principal do UOL. Todas as palavras linkadas na barra inicial e na coluna da esquerda da tela remetem o hiperleitor para dentro do portal, para dessa forma fazê-lo conhecer e utilizar os serviços do portal que lá estão disponíveis. Por serem ofertas de serviços, há poucos hiperlinks que remetem o usuário a outros locais na web. 


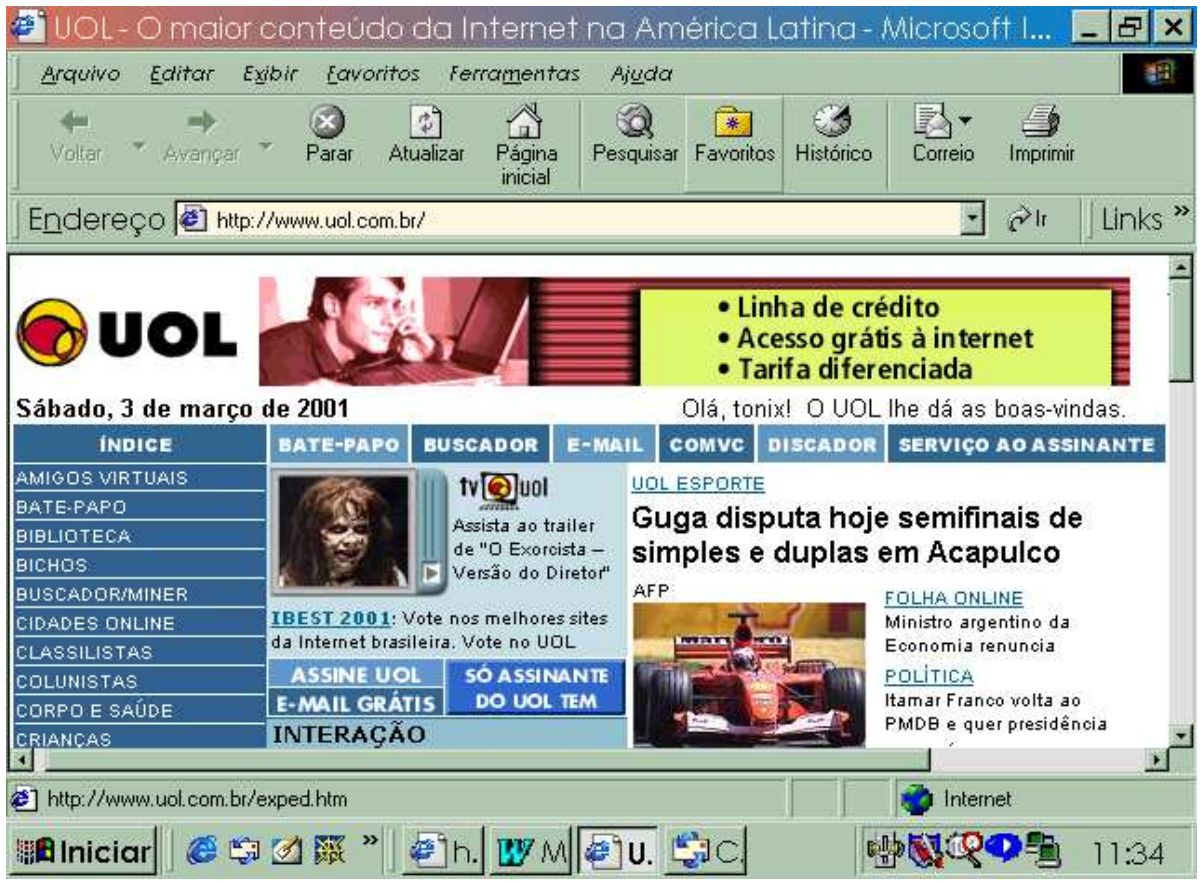

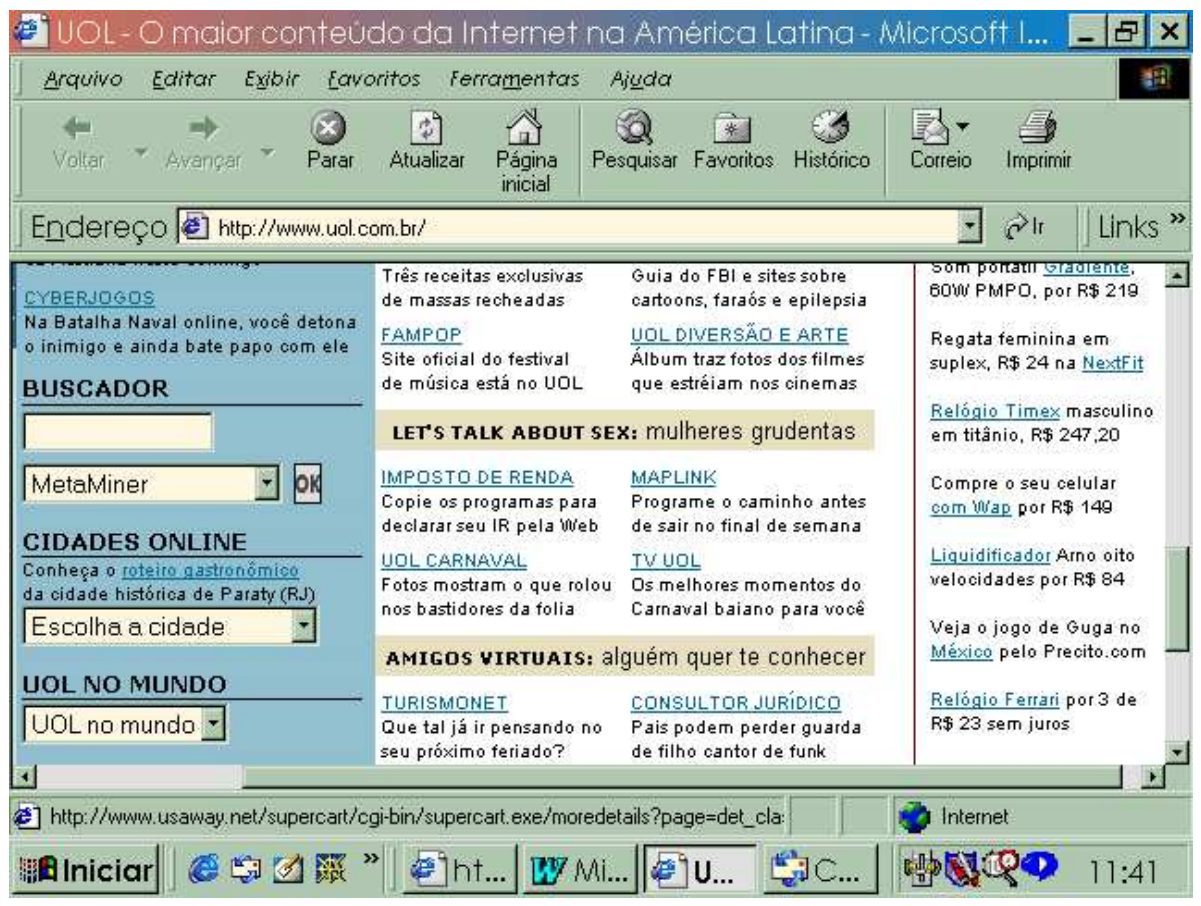




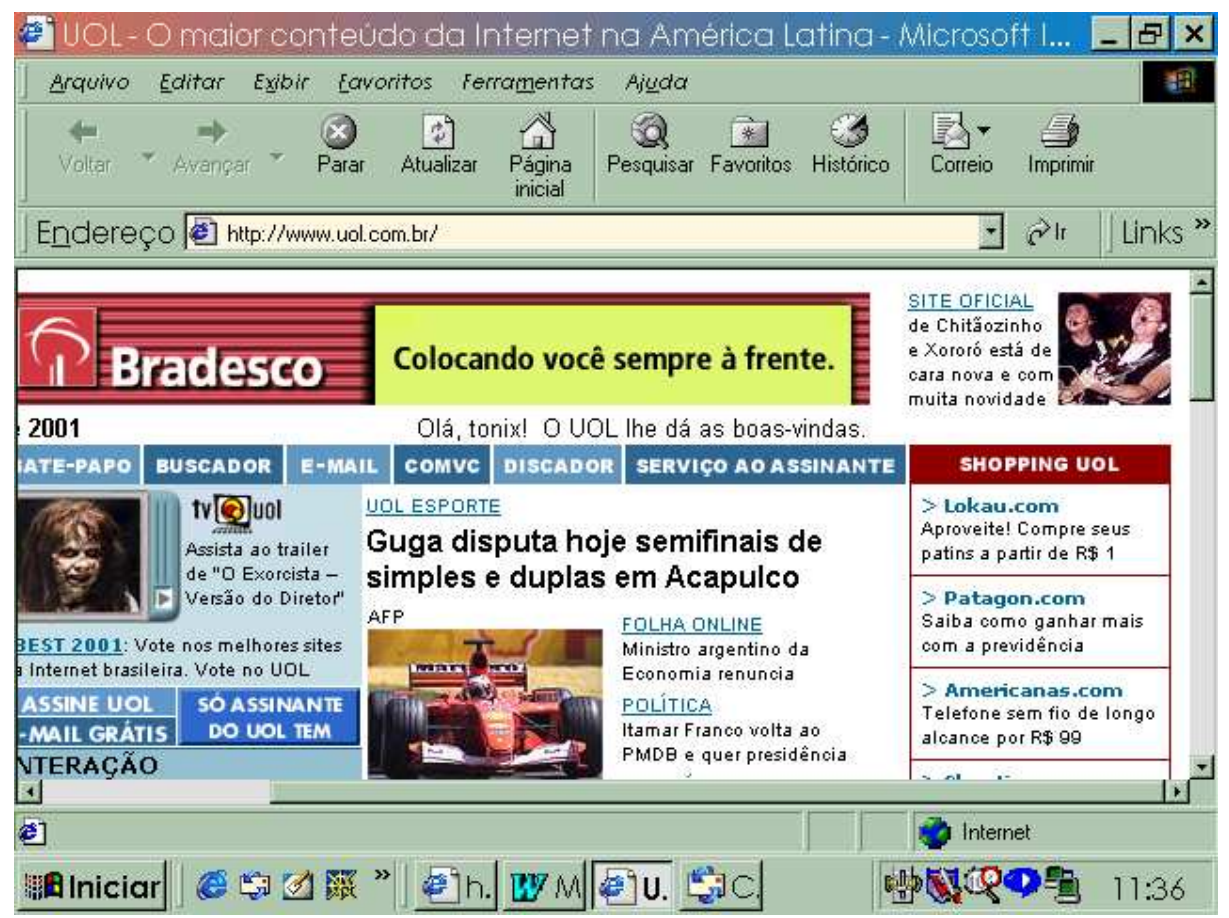

As localizadas no centro da tela nem sempre levam o usuário para as páginas internas. Em contrapartida, a maioria das formas enunciativas linkadas que ocupam o lado esquerdo da tela, por se tratar em geral de propagandas, "dicas" e "sugestões", remetem sim o hiperleitor a sites outros fora do domínio do portal. Basta passar a seta do mouse sobre a palavra ou ícone linkado, que logo aparece, na parte inferior da janela do navegador, o endereço no qual está hospedado aquele website em forma de hiperlink.

\section{b) Referenciação Digital Pan-Hipertextual}

Já os hiperlinks que levam o usuário às páginas externas de um website apresentam-lhe efetivamente propostas de leituras e caminhos de navegação a trilhar com possibilidade de visitas a lugares diversos na rede digital. Eles põem o hiperleitor em "contato" direto com discursos, posições e saberes vários. Disponibilizam-lhe um universo inteiro de conhecimento que pode ser acessado através de um simples premerde-mouse.

Os hiperlinks pan-hipertextuais tornam possível ao usuário uma visão panorâmica do universo, transformando-o em sujeito mais autônomo e independente para analisar os vários aspectos de uma mesma questão e decidir com mais talante que posição 
assumir, dispensando, assim, intermediários, censores e "iluminados", até então os únicos autorizados a opinar sobre um dado tema.

Toda uma gama de dizeres torna-se desvelável pelo funcionamento eficiente destas ferramentas de interconexão virtual. Conseqüentemente, a cada click, uma diferente aventura, a cada mergulho eletrônico, uma nova descoberta ou consolidação de antigas convicções, crenças ou atitudes. A visão de mundo e de homem do usuário do hipertexto tende a se ampliar e a se flexibilizar constantemente conforme as demandas sociais e cognitivas que emergem a sua frente.

\section{A FUNÇÃO DÊITICO-VETORIAL DOS HIPERLINKS}

Portanto, a função fundamental dos hiperlinks parece mesmo ser a de VETORIAR, isto é, indiciar veredas virtuais a serem percorridas pelo hiperleitor no ciberespaço, apontar lugares outros onde se possa encontrar mais informações que ajudem a compreender o mundo e, por conseguinte, a viver um pouco melhor.

Todo hiperlink tem por função primeira indicar, sugerir caminhos, propor trajetos ao hiperleitor. Ele funciona originariamente como um apontador enunciativo digital no Hipertexto, e, por essa razão, é também um focalizador de atenção por excelência, aparecendo perceptivelmente destacado, ou seja, normalmente sublinhado ou em cor diferenciada em relação a outros enunciados verbais e visuais na tela. Toda essa roupagem que reveste o hiperlink torna-o um atrativo e poderoso recurso de sedução do leitor e de emulação do seu desejo de conhecer os segredos que se escondem "por trás" dele.

Enquanto seduz os hiperleitores, o hiperlink aponta visualmente para um lugar “concreto", atualizável no espaço digital. O sítio indicado existe virtualmente, pode ser acessado por qualquer um, embora não seja materializável, tangível fisicamente. Ele conduz veloz e facilmente o hiperleitor a lugares na rede cujo acesso seria muito mais penoso e demorado, ainda que não impossível, caso a operação de pesquisa fosse realizada através de um serviço de busca. Geralmente os portais que oferecem serviços de pesquisa na rede utilizam simultaneamente a tecnologia de algoritmos procedurais e spiders, que são robôs programados para varrerem bancos de dados da Internet até encontrarem a informação procurada, operação informática que leva alguns minutos para ser processada.

Com efeito, o hiperlink trabalha fundamentalmente como elemento indexador de outros Hipertextos, e não somente como referenciador de entidades lingüísticas intrahipertextualmente. Ele instala, no seu interior, outros dizeres hipertextualizados; opera como incorporador virtual de páginas eletrônicas inteiras dotadas de informações que transcendem ao espaço da co-textualidade imediata.

O hiperlink dêitico, então, operacionaliza as imprescindíveis interseções entre textos/discursos que já estejam hipertextualizados, e, ao mesmo tempo, articula, através deles, posições disparatadas em torno de uma mesma questão, evidenciando a presença de beligerâncias e divergências intelectuais tão salutares para qualquer sociedade que 
valorize a livre expressão de pensamento dentro de uma atmosfera em que prevalece o Estado Democrático de Direito.

Nesta perspectiva, o hiperlink com função dêitica assume um caráter essencialmente EXOFÓRICO, prospectivo, ou seja, está sempre ejetando o hiperleitor para fora e para um depois do dito, para um além daquela página virtual, jogando parte de suas expectativas de completude de compreensão em outros Hipertextos ali referendados.

O hiperlink parece especular constantemente um movimento de projeção, de êxodo não definitivo do hiperleitor dos limites do lido, sugere-lhe insistentemente atalhos que auxiliem a apreensão de sentido, ou seja, apresenta rotas alternativas, caso o hiperleitor queira pormenorizar aspectos e preencher on-line lacunas de interpretação que, porventura, venham à tona durante o processamento da leitura no Hipertexto.

Enquanto elemento dêitico, o link se constitui como um grande holofote catalisador de olhares, cuja tarefa é mostrar enfaticamente Hipertextos outros a serem visitados, lidos e considerados, atuando sob o efeito-ímã da intertextualidade/interdiscursividade constitutiva da linguagem. A sua natureza essencialmente relacional ratifica o princípio das vinculações necessárias entre textos/discursos que veiculam idéias/ideologias carregadas de verdade/poder que impõem como são ou devem ser as relações interinstitucionais e interpessoais na sociedade da informação.

É papel dos links-dêiticos costurar essa colcha múltipla de Hipertextos retalhados e encharcados de discursos ideologizados que se avolumam na grande rede de computadores, hoje já se aproximando dos dois bilhões de páginas eletrônicas indexadas.

Portanto, apontar visualmente, conduzir cognitivamente e levar virtualmente o leitor para uma outra esfera também hipertextual parecem ser as atribuições fulcrais dos hiperlinks, as razões centrais de sua criação e existência no Hipertexto.

Os hiperlinks dêiticos operaram ainda como táticas retóricas de cercar um determinado problema por todas as angulações e perspectivas imagináveis em que ele possa ser visualizado e entendido, já que a indicação "linkada" se dá geralmente entre Hipertextos que tratam do mesmo tópico e, assim, se complementam ou se refutam, se reafirmam ou se contradizem. Eles realizam uma espécie de proposta-convite ao relativo esgotamento das inúmeras vertentes e visões pelas quais um mesmo assunto pode ser abordado.

Sabe-se, pois, que um link leva a outro, que, por sua vez, leva a outro formando uma grande conexão em cascata, que de tão extensa pode ficar perdida no horizonte com risco de escapar ao alcance do olhar humano, gerando a ilusão de vinculação semfim. Por esse motivo, acessá-lo e explorá-lo em toda a sua plenitude não é tarefa fácil, passível de realização por qualquer um. O criador de tais hiperlinks sempre pressupõe que o usuário detenha um certo conhecimento de navegação na rede, i.e., já possua alguma experiência com leitura não-linear em páginas digitais. 
A exemplo dos dêiticos discursivos que, segundo Marcuschi (1997:170), "não trazem nada para os enunciados sob o ponto de vista proposicional, mas sim sob o ponto de vista da qualidade do foco", os links dêiticos, além de monitorar cognitivamente e lançar luz sobre o tópico, acrescentam informações globais e adicionam dados gerais ao conteúdo em discussão, uma vez que ultrapassam o limite de um único Hipertexto e conduzem a reflexão para muitos outros blocos discursivos hipertextualizados nos quais se refratam e para os quais se remetem.

Em uma palavra, o link dêitico transborda totalmente a discussão para além de um Hipertexto. Ele é o instrumento virtual pelo qual se "materializa" o complexo processo que só é feito abstratamente, mentalmente, que são as inúmeras e inevitáveis associações, vínculos e ligações quase instantâneas entre discursos e saberes afins ativados pelos leitores, quando lêem hipertextual e enciclopedicamente.

\section{CONCLUSÃO}

Em síntese, poderíamos dizer que, por não haver forma única de relacionar os referentes no mundo real ou virtual, mas uma plasticidade discursivo-cognitiva que se amolda à necessidade contextual, a referenciação digital conquista o seu lugar no universo virtual por apresentar-se como uma maneira fluida de fazer referenciação. $\mathrm{O}$ que se nos apresenta como inovação neste modo digital de referenciar no Hipertexto é, certamente, a presença dos hiperlinks e a sua performance como elemento dêiticovetorial na constituição do sentido e na construção da coerência no Hipertexto. Isto ocorre por duas razões: 1) devido à sua natureza de dispositivo técnico-informático, que permite efetivar ágeis deslocamentos de navegação on-line por cais de informações nunca dantes aportados; 2) por sua capacidade de realizar referenciações digitais co e pan-hipertextualmente (i.e., para dentro e para fora do website), as quais possibilitam ilações mentais e acessos virtuais instantâneos do hiperleitor a Hipertextos outros com os quais mantém necessariamente laços cognitivos e retórico-argumentativos ou de qualquer outra ordem.

\section{$\overline{\text { REFERÊNCIAS }}$}

ANTOS, Gerd. (1997). Os textos como formas constitutivas do saber. Sobre algumas hipóteses para a fundamentação da lingüística de texto à base de uma teoria evolucionária. In: Antos, Gerd \& Tietz Heike. (1997). O futuro da lingüística de texto. Tradições, Transformações, Tendências. Tübingen:Niemeyer. RGL 188. pp. 43-65.

APOTHÉLOZ, D. e REICHLER-BÉGUELIN, M-J. (1995). Construction de la référence et strategies de designation. In: BERRENDONNER, A \& M-J REICHLER-BEGUELIN (eds). 1995: 227-271.

BEUGRANDE, Robert de. (1997). New Foundations for a Science of Text and Discourse: Cognition, Comunication, and Freedom of Access to Knowledge and Society. Norwood, N.J., Ablex.

BUSH, Vannevar. (1992). As We may Think. In: The Atlantic Monthly, 1945, reeditado em Nelson Theodore Holm, Literary Machine 93.1, Mindful Press, Sausalito. 
NELSON, Theodore Holm, Literary Machines 93.1, Mindful Press, Sausalito.

CLÉMENT, Jean. (1995). Du Texte à l'hipertexte: vers une épistemologie de la discursivité hypertextualle. Http://hypermidia.univ-paris8.fr/Jean/articles/discursi- vité. htm.

KOCH, Ingedore, V. G. (1997).O Texto e a Construção dos Sentidos. São Paulo, Contexto.

KOCH, Ingedore. \& MARCUSCHI, L. A. (1998). Processos de Referenciação na Produção Discursiva. DELTA, 14 (n ${ }^{0}$ Especial).1998:169-190.

MARCUSCHI. L. A. (1997). A dêixis discursiva como estratégia de monitoração cognitiva. In: KOCH \& BARROS, Tópicos em Lingüística de Texto e Análise da Conversação, 1997, Edufrn, Natal, RN.

MODADA, Lorenza \& DUBOIS, D. (1995). Construction des objets de discours et categorization: une approche des processus de referenciation. In: BERRENDONNER, A \& M-J REICHLER-BEGUELIN (eds). 1995:273-302.

NELSON, Theodore Holm. (1992). Literary Machines 93.1, Mindful Press, Sausalito.

XAVIER, Antonio Carlos. (1999a). Hipertexto: Novo Paradigma Textual? www.unicamp.br/ hytex (1999b). Leitura, Texto e Hipertexto. www.unicamp.br/ hytex. 